\title{
ANALYSIS OF THE DETECTION OF MALIGNANT BREAST CANCER LESIONS IN WOMEN IN THE STATE OF GOIÁS IN THE PERIOD 2010-2013
}

Paula de O. C. Queiroz¹, Nayara P. A. Oliveira1, Fernando C. R. Pinheiro1', Vitória N. Macedo', Hygor A. P. Dutra 'Universidade Federal de Goiás - Goiânia (GO), Brazil.

Objective: To analyze the detection of malignant lesions of breast cancer, through the following indicators: clinical breast examination and mammography, in women in the state of Goiás from 2010 to 2013. Methodology: This is a descriptive study using data from the Breast Cancer Information System (SISMAMA). Results: It was observed that in the period of 2010 the detection of malignant lesions by clinical examination overlapped the imaging method (mammography) in $17.88 \%$. In 2011, this difference increased to $24.23 \%$. Following the same trend, this difference increased to $53.53 \%$ and $59.83 \%$, in the years of 2012 and 2013, respectively. Conclusion: The results demonstrate that the detection of malignant lesions by clinical examination in the breast overlaps mammography, evidencing a failure in the early diagnosis of breast cancer in Goiás. Some limitations in adherence to mammography screening are misinformation about the examination by the target public, the lack of training of health teams and the lack of machines in Brazil associated with a poor distribution of machinery. Since mammography is the only method capable of reducing breast cancer mortality in an absolute way, it is fundamental to implement strategies to cope with the low adherence to this imaging examination. 